УДК 347.97

DOI 10.18413/2712-746X-2020-45-1-123-132

\title{
К ВОПРОСУ ОБ УЧАСТИИ СУДЕЙ В СОЦИАЛЬНЫХ СЕТЯХ В РАМКАХ СТАТУСА СУДЬИ
}

\section{THE ISSUE OF PARTICIPATION OF JUDGES IN SOCIAL NETWORKS IN THE FRAMEWORK OF THE JUDGE STATUS}

\author{
Л.Е. Факеева \\ I.E. Fakeeva \\ Амурский Государственный университет, \\ Россия, 675027, г. Благовещенск, ул. Игнатьевское шоссе, 21 \\ Amur State University, \\ 21 Ignat'evskoe shosse, Blagoveshchensk, 675027, Russia \\ E-mail: larisafakeeva@yandex.ru
}

\begin{abstract}
Аннотация
В настоящее время существует огромное количество социальных сетей, в каждой из который зарегистрированы миллионы людей, в том числе и судьи. Отсутствие понимания того, что допустимо судьям на просторах интернета, а что несовместимо с их высоким статусом, свидетельствует об актуальности изучения этической стороны участия судей в социальных сетях и требует установления определенных ориентиров поведения судей в интернет-сообществе, где, как и при отправлении правосудия, формируется их имидж. Автором обосновывается, что социальные сети выступают средством информирования населения о работе судов и правового просвещения населения, поэтому создаваемый на просторах интернета образ судьи влияет на отношение граждан к правосудию в целом. Рассмотрены этические проблемы, возникающие в связи с участием судей в социальных сетях. Проанализированы пределы допустимого поведения судей в интернет-пространстве с учетом специального статуса и в условиях его продолжающейся модернизации. Освещены подходы к поведению судей в социальных сетях. С учетом характеристики последствий законодательно установленных ограничений статуса судьи сделаны выводы о необходимости помощи судьям в определении возможного поведения в интернете путем установления критериев такого поведения, в том числе через развитие и конкретизацию Кодекса судейской этики.
\end{abstract}

\begin{abstract}
Nowadays we have a huge number of social networks, there are registered millions of people including judges. The lack of understanding of what is allowed for judges on the Internet, and what is incompatible with their high status, indicates the relevance of studying the ethical side of judges' participation in social networks and requires the establishment of certain guidelines for judges' behaviour in the Internet community, where, as in the administration of justice, they form their image. The author substantiates that social networks act as a means of informing the population about the work of the courts and legal education of the population, therefore the created on the Internet image of a judge expands the attitude of citizens to justice in general. We will consider ethical issues that arise in connection with the participation of judges in social networks, will analyze the limits of the acceptable behaviour of judges in the Internet space, taking into account the special status and in the context of its ongoing modernization, will highlight approaches to the behaviour of judges on social networks. Given the characteristics of the consequences of legislatively established restrictions on the status of a judge, we will draw conclusions about the need to help judges in determining possible behaviour on the Internet by establishing criteria for such behaviour, including through the development and specification of a Code of Judicial Ethics.
\end{abstract}


Ключевые слова: статус судьи, этика судьи, модернизация, социальные сети.

Keywords: the status of the judge, ethics of the judge, modernization, social networks.

\section{Введение}

В России в 1991 году началось масштабное преобразование судебной системы, которое привело к модернизации - приведению в соответствие требованиям современности всех её элементов: судопроизводства, судоустройства и статуса судьи. Справедливым является мнение Туманова В.А. о том, что статус судьи занимает особое место в общественном сознании, отражает проблемы правосудия как особой сферы человеческой деятельности [Туманов и др., 1991, с. 6], и суждение Лукашевой Е.А., касающееся авторитета судьи - чем выше роль и авторитет судьи, тем выше в государстве уровень законности и демократии, тем больше защищены от посягательств права и свободы человека [Лукашева и др., 2009, с. 321].

Правовой статус судьи включает в себя профессиональную этику, прошедшую в своем развитии три периода: дореволюционный - с 1864 года (появление независимых профессиональных судей) по 1917 гг., советский - с 1917 года по 1993 год, современный с 1993 года по настоящее время. И на каждом этапе развития этики к судьям и к их профессиональному и внеслужебному поведению предъявлялись все новые требования. В первый период были объявлены недостойными звания судьи все предосудительные и несогласные с нравственностью поступки. Второй период, связанный с Октябрьской революцией 1917 года, кардинально изменил предъявляемые к судье требования, указав главную задачу правосудия - борьбу с эксплуататорами и отрицая нравственные, этические начала судебной деятельности. С 60-х годов прошлого века появилось понятие «судебная этика», и к началу третьего периода выделилась профессиональная этика юриста, в том числе судейская этика [Лагутин, 2016].

Действующий в настоящее время Кодекс судейской этики 2012 года, устанавливающий нормы и принципы поведения судей, является результатом многолетней работы советских и российских ученых и юристов. Однако в период, когда положения Кодекса только обсуждались, интернет-ресурсы в России повсеместно еще не были развиты, что, вероятно, явилось причиной отсутствия в Кодексе критериев поведения судей в социальных сетях. Председатель Совета судей РФ Момотов В.В., говоря о судьях и социальных сетях, указал на то, что судьи должны самостоятельно определять и ограничивать свое присутствие в социальных сетях [Момотов, 2018]. Но виртуальный мир сейчас является неотъемлемой частью жизни, он участвует в социализации любого человека, в том числе судей [Хазиева, 2014]. По данным ВЦИОМ ${ }^{1}$, свыше половины россиян практически ежедневно пользуются социальными сетями и мессенджерами по отправке сообщений. Нельзя не согласиться с тем, что в настоящее время формируется информационное общество, в котором средой сбора и обмена информацией являются телекоммуникационные сети, а правовую культуру общества наряду с правосудием формирует и интернет [Лебедева, 2004].

Учитывая наличие определенных ограничений во внеслужебной деятельности в силу специального статуса, возникает вопрос: могут ли судьи пользоваться социальными сетями? Ответ, безусловно, положительный, ведь к нарушению этических норм сам факт участия в социальных сетях не приводит. Также нельзя не учитывать, что социальные сети способствуют информированию населения о деятельности судебной системы, повышению прозрачности судов, могут использоваться для правового просвещения населения, и, вообще, стали частью мировой культуры, поэтому «изоляция» судей от участия в глобальной информационной среде невозможна и не имеет смысла.

1 Пользование интернетом. ВЦИОМ. URL: https://wciom.ru/news/ratings /polzovanie _internetom/ (дата обращения 14.06.2019). 
Поведение российских судей в социальных сетях до настоящего времени не регламентировано, и судьи, не имея каких-либо ориентиров в этой сфере, нередко одним неудачным постом наносят урон не только себе, но и авторитету судебной власти в целом. Несмотря на случаи прекращения полномочий судей вследствие их действий в социальных сетях, признанных органами судейского сообщества несовместимыми со статусом судьи, проблема участия судей в таких интернет-сообществах в России практически не изучена. Этическая сторона поведения судей на просторах глобальной сети пока не нашла большого интереса у ученых-правоведов и практикующих юристов, и каких-либо глубоких исследований на эту тему нет. Но поскольку интернет-пространство является одной из областей жизнедеятельности судьи, где формируется его имидж, вопрос о том, что следует считать уместным, и где для судьи в социальных сетях грань дозволенного, крайне актуален. Изучение этической составляющей участия судей в социальных сетях направлено на утверждение необходимости установления для судей критериев такого поведения.

\section{Пределы допустимого поведения судей в социальных сетях}

Судья не может и не должен находиться в социальном и правовом вакууме, но должен понимать, что его действия находятся под контролем, в рамках которого судья может быть подвергнут взысканиям вплоть до прекращения полномочий. В отличие от других пользователей социальных сетей, судьи в своем поведении ограничены не только правовыми, но и этическими проблемами, тогда как пределы этих ограничений и рамки допустимого поведения судей в глобальной сети могут пониматься по-разному - от публикации не соответствующих статусу судьи сведений до полного отказа от участия в социальных сетях. Общаясь в интернет-пространстве, в том числе через социальные сети, судья, согласно действующим положениям Кодекса судейской этики, должен самостоятельно определять, какие из опубликованных им сведений соответствуют, а какие - не соответствуют его высокому статусу. То есть, фактически критерии оценки пределов допустимого поведения судьи в социальных сетях отданы «на откуп» самим судьям. Судьи, как предусмотрено Кодексом судейской этики, Законом о статусе судей, должны избегать всего, что могло бы умалить авторитет судебной власти и достоинство судьи. Но каждый судья как отдельный человек имеет свои собственные этические представления, и в отсутствие нормативно установленных ориентиров оценка отдельным судьей своего участия в социальных сетях может не совпадать с ожидаемым от него поведением. Противоречия, возникающие в связи с имеющимися у судьи как личности нравственными правилами поведения на просторах интернета и профессиональными этическими установками, необходимо устранять. И здесь возникают вопросы: какую информацию сам судья считает возможной публиковать в интернете, и насколько его мнение о допустимости этой информации совпадает с мнением судейского сообщества?

Известна ситуация с отказом М. в назначении на должность судьи Арбитражного суда в 2014 году, когда обсуждалось размещение претендентом на странице в социальной сети фотографии в образе подвыпившего полуобнаженного пирата с подбитым глазом и татуировкой на левом плече, а также фото М. на сайте Pravotoday с высунутым языком и надписью «Никогда не предполагал, что надену судейскую мантию». Судейским сообществом в лице Высшей квалификационной коллегии судей РФ такое изображение личной фотографии и комментарий к ней в социальной сети и на юридическом портале признаны не соответствующими правилам поведения судейской этики. Это решение органа судейского сообщества было поддержано Верховным Судом РФ ${ }^{1}$. При этом М., давая объяснения в судебном заседании Верховного Суда РФ, указал, что не считает данные изображения умаляющими авторитет судебной власти, и пояснил, что они лишь отображают раз-

1 Полуобнаженный пират не стал российским судьей : Право.py. URL: https://pravo.ru/court_report/view/111935/ (дата обращения: 20.06.2019). 
ные стороны его жизни; первый снимок был шуточным, сделан во время его участия в капустнике с женой и детьми и находился в закрытой группе, а второй - сделан еще в 2010 году, до назначения на должность судьи.

Примечательно, что к тому времени М. имел стаж работы в должности судьи более 11 лет, зарекомендовал себя грамотным и квалифицированным судьей, имел хорошую теоретическую подготовку и практический опыт работы, добросовестно исполнял свои обязанности, обеспечивал хорошее качество отправления правосудия, постоянно повышал свой профессиональный уровень и имел ученую степень кандидата юридических наук. Налицо явное противоречие в оценке допустимых пределов участия в социальных сетях у самого судьи (довольно опытного, имеющего высокий уровень теоретической подготовки, понимающего, что такое есть судейская этика), и у органов судейского сообщества.

Еще одно решение Дисциплинарной коллегии Верховного суда РФ состоялось в 2014 году и касалось судьи П., которая в свободном доступе на своей странице в социальной интернет-сети «Одноклассники» разместила фотографии, сделанные в зале судебного заседания на фоне герба РФ и флага РФ с надписью «Очень разная я, но ведь Женщина! И такую меня создал Бог! И, как ветер порой переменчива, видно, Черт тут немного помог», фото с похожим на молоток предметом в руке на фоне герба РФ и надписью «Как дам по лбу всем, кто будет на меня наезжать!», снимок со статуэткой Фемиды в руках на фоне герба РФ и подписью «Мне не важно, что вы обо мне думаете... Меня это не радует и не огорчает. Радует одно ... что вы еще думать не разучились», фото с изображением П. в зале судебного заседания в кресле судьи с поставленными на стол ногами и надписью «Я, конечно, не совершенство, но шедевр еще тот!». Кроме того, личная стартовая страница П. содержала слова: «Как много тех, с кем можно лечь в постель... Как мало тех, с кем хочется проснуться... И утром, расставаясь, обернуться, И помахать рукой, и улыбнуться». Судья П., обжалуя решение региональной Квалификационной коллегии судей в Дисциплинарную коллегию ВС РФ, указала, что данные фотографии носят шутливый, сугубо личный характер, находились на личной странице, защищенной настройками приватности, а размещая на своей Интернет-странице выдержку из стихотворения Э. Асадова, она не причиняла ущерб авторитету судебной власти.

Действия П. были признаны игнорирующими требования Кодекса судейской этики и причинившими ущерб авторитету судебной власти. При этом не было отнесено к дисциплинарному проступку размещение П. в социальной сети фотографии на фоне флага РФ с надписью «Под знаменем России»» как не свидетельствующее о нарушении норм поведения судьи.

Следует отметить, что П. к тому времени имела стаж работы по юридической профессии 30 лет, а в должности судьи работала около 12 лет. Размещая ряд фотографий в социальных сетях, П., имея огромный опыт юридической и судейской работы, полагала все снимки соответствующими этическим нормам поведения судьи, тогда как по мнению органа судейского сообщества этим требованиям соответствовал только один снимок.

Что в приведенных случаях в частности, и вообще, в принципе является причиной таких разных оценок поведения судьи в социальных сетях самим судьей и органами судейского сообщества? Причин, безусловно, много. Но одной из них, возможно, является отсутствие критериев такого поведения судьи как специального субъекта права в социальных сетях; поведения, которое, соответствовало бы правомерным ожиданиям общества относительно статуса судьи и формировало основанный на доверии к судье авторитет [Орлова, 2017].

\section{Формирование судьями социальных связей в интернете}

Проблемы доверия к судьям могут возникать при формировании судьей социальных связей, в том числе через социальные сети, путем создания «списков друзей», в частности, из числа юристов. Выделяют три подхода относительно этической стороны добав- 
ления пользователей в друзья юристов - жесткий, умеренный и либеральный ${ }^{1}$. Согласно жесткому подходу судья может добавлять в друзья других юристов при условии, что они не могут в будущем являться участниками судебных разбирательств у этого судьи. Умеренный подход к данному вопросу допускает возможность добавления судьей в друзья человека, который участником процесса по находящемуся в производстве судьи делу либо представителем участвующих лиц ранее не являлся и в настоящее время не является. В соответствии с третьим, либеральным подходом обозначение человека в качестве друга в социальных сетях само по себе свидетельством личных взаимоотношений с судьей не является и на отправление правосудия повлиять не может, а медиа-«дружба», как правило, не так значима, как традиционная.

Реализация на практике требований жесткого и умеренного подхода представляет большую сложность. Особенно это касается отдаленных населенных пунктов, где правосудие отправляют несколько судей районного суда и 2-3 мировые судьи, где еще меньшим может быть количество адвокатов и юристов, оказывающих юридические услуги. В таких условиях исключение участия юриста - виртуального «друга» судьи - в будущем рассмотрении судьей какого-либо дела не всегда осуществимо. При умеренном подходе вероятность участия такого юриста в рассматриваемом судьей деле в будущем значения не имеет, существенным является участие такого лица в рассмотрении судьей дела ранее или в настоящее время. Но и в этом случае вероятность участия адвоката, иного представителя участника процесса у судьи, «другом» которого в социальных сетях является такой юрист, особенно в небольших населенных пунктах, очень высока. Кроме того, работая в суде даже непродолжительное время, судьи не могут не знать многих адвокатов, юристов, и, поддерживая с ними профессиональное общение, пользуясь социальными сетями, вполне могут принять приглашение такого юриста на добавление в список виртуальных друзей. Поэтому наиболее верным представляется третий, либеральный подход формирования судьей социальных связей в социальных сетях, при котором, однако, оценивать виртуальную дружбу судьи с юристами следует с учетом всех фактов, в частности решения вопроса о том, следует ли судье информировать участников процесса о виртуальной дружбе с юристом, принимающим участие в рассмотрении дела. Данный подход, кроме того, не освобождает судей от осуществления контроля за своими страницами в социальных сетях, в том числе и в тех, которые закрыты от просмотра другими пользователями. Социальные сети предусматривают возможность закрывать свои страницы от просмотра других людей, однако размещаемая судьей информация остается доступной для добавленных в списки друзей, которые могут передать её другим лицам. Судье при участии в социальных сетях следует помнить, что в глобальной компьютерной сети, несмотря на усилия пользователей сохранить личные данные, нет ничего «частного». Все интернет-публикации, будь то тексты, фотографии, аудио- или видеозаписи, остаются на просторах интернета в течение длительного времени, даже когда пользователь о них уже забыл, поэтому судьи не должны ожидать никакой конфиденциальности от социальных сетей, в которых настройки приватности (как например, в Facebook) могут быть изменены в одностороннем порядке. Кроме того, как правило, все, что скрыто, уже само по себе вызывает подозрения, и, если тайное станет явным, может пострадать репутация судьи [Cooper, 2014].

Наиболее правильной представляется полная открытость страниц судей в социальных сетях, но с постоянным контролем над ними, поскольку, размещенная судьей в социальных сетях информация может быть «вырвана из контекста», и, являясь, например, шуткой, преподнесена другим пользователям в искаженном виде. Все опубликованные судьей материалы могут свободно распространяться без его разрешения, а проставленные

${ }^{1}$ Выступление Председателя Совета судей РФ В. В. Момотова на втором заседании клуба имени Замятнина по теме «Судья и социальные сети» : Совет судей Российской Федерации. URL: http://www.ssrf.ru/news/vystuplieniia-intierv-iu-publikatsii/28718 (дата обращения: 14.06.2019). 
судьями в социальных сетях «лайки» и комментарии на страницах других пользователей могут расцениваться как одобрение их действий и поступков.

Интернет справедливо признается новым пространством человеческого самовыражения и общения, сферой социальной деятельности, а информационные отношения, возникающие с использованием сети интернет - существующими в электронной форме в киберпространстве, общественными отношениями [Рассолов, 2009]. Поэтому любая запись, сделанная судьей в социальной сети, особенно о применении или толковании той или иной нормы, равнозначна публичному выступлению, и высказывание судьей на просторах интернета своей позиции, в том числе по правовым вопросам, может привести к проблемам этического характера.

\section{Этические «ловушки» для судей в социальных сетях}

Социальные сети создают для судей уникальные этические «ловушки», о существовании которых судья может и не догадываться. Так, в социальных сетях зачастую участвуют родственники судей, страницы которых также являются «территорией ответственности» судьи. Думается, что родственникам судей не следует указывать в социальных сетях на свое родство с судьей, размещать фото- и видеоматериалы с указанием расположения жилья, идентификацией автомобилей, в частности из соображений безопасности, поскольку интернет открывает большие возможности для оказания давления на судью. Судья, в свою очередь, не должен позволять членам своей семьи неподобающим образом влиять на его действия, связанные с выполнением им полномочий судьи [Нешатаева, 2011]. Родственникам судей следует воздерживаться от публичной демонстрации в социальных сетях предметов роскоши, поездок на дорогие курорты, посещения престижных ресторанов и т.п., поскольку это умаляет авторитет судебной власти, даже если эти действия совершаются на законно полученные денежные средства [Момотов, 2018].

Нельзя не сказать и о будущих судьях. Судейский корпус все больше «молодеет» и формируется в новой ментальности - по данным Института проблем правоприменения, средний возраст кандидатов на должность судьи составляет 35,3 года, возраст 90 \% кандидатов не превышает 42 лет [Дмитриева, Савельев, 2019]. В связи с повышением престижности работы судьи все больше будущих юристов задумываются о судейской карьеpe. В молодежной, в том числе студенческой, среде Всемирная глобальная сеть как особая реальность и часть информационного общества сформировала новые формы коммуникаций - через мессенджеры и социальные сети, поэтому участие будущих судей в социальных сетях задолго до облачения в судейскую мантию закономерно. Вполне возможно размещение ими в социальных сетях фото-, видеоматериалов об участии в праздниках, корпоративах, на отдыхе, в том числе с людьми, которые в будущем могут стать адвокатами, прокурорами, сотрудниками правоохранительных органов и т.п. В этом случае возникает вопрос оценки указанных сведений с точки зрения взаимоотношений судьи с этими людьми в последующем, в период отправления правосудия. Верным представляется разъяснять студентам юридических ВУЗов необходимость проявления осмотрительности и контроля за характером информации на своих страницах в социальных сетях в соответствии с требованиями профессиональной этики юриста уже в период обучения в ВУЗе.

Еще одна этическая «ловушка» для кандидатов на должность судьи и судей, в основном женщин, касается семейного положения судьи как важнейшего показателя психологического и социального благополучия человека. В России довольно много женщинсудей не состоят в браке - только в Архангельской области в 2007 году количество женщин - кандидатов на должность судьи, не состоящих в браке, составляло 63 \%, и после вступления в должность увеличивалось на $13 \%$. В Ямало-Ненецком автономном округе в 2010 году около 50 \% женщин-судей были незамужними, а 16 \% из них никогда не состояли в браке.

И количество женщин-судей в судейской среде постоянно возрастает - если в 1994 году их доля среди кандидатов, назначенных на должность судьи, составляла 58,5 \%, в 2010 году - 61,8 \%, то в 2016 году - уже 73,6 \%. При этом, согласно проведенным исследованиям, мир среднестатистической российской судьи (мирового или районного суда) 
замкнут на работе и близких, а на общение с друзьями, путешествия, полноценный отдых, как правило, у судьи времени не хватает [Волков, 2015]. В условиях социальной изоляции, загруженности на работе, ограниченного времени на отдых, особенно в небольших населенных пунктах, судья может искать партнера для создания семьи в социальных сетях, в том числе на сайтах знакомств. Вопрос о соответствии такого способа поиска судьей семейного счастья требует обсуждения. В любом случае, судье не следует обозначать себя в социальных сетях как судью, поскольку, указание на занимаемую судейскую должность в социальных сетях с учетом определенных обстоятельств может привести к умалению авторитета судебной власти.

Пользователями социальных сетей могут являться и судьи в отставке, за которыми сохраняются звание судьи, гарантии личной неприкосновенности, принадлежность к судейскому сообществу и, следовательно, обязанность соблюдения требований Кодекса судейской этики. Поведение судей в отставке в социальных сетях, возможность добавления ими в друзья адвокатов, юристов, прокуроров, других лиц, которые принимали участие в уже рассмотренных ими делах, не регламентированы, пределы ограничений такого поведения, критерии его оценки (как вызывающее (не вызывающее) сомнение в объективности по уже рассмотренным делам и способное (не способное) повлиять на существо уже принятых судебных постановлений) не установлены.

\section{Определение критериев этической стороны участия судей в социальных сетях}

Интернет не имел аналога в прошлом, поэтому какая-либо законодательная регламентация правил информационного обмена в кибернетическом пространстве для лиц со специальным статусом отсутствует. И фактически в настоящее время происходит адаптация традиционных правовых норм к отношениям, связанным с использованием глобальных электронных сетей. Вопросы о том, должно ли поведение судей в электронных сетях регулироваться судейским сообществом, если да, то в каких пределах и каким путем, в России остаются открытыми.

Пути установления критериев поведения судей в социальных сетях могут быть разными - принятие новых нормативных актов, модернизация уже существующих, совмещение традиционных базовых установок с новыми правилами, разъяснения и комментарии действующих норм, обращение к международному опыту, тем более, что в ряде стран уже приняты рекомендации по использованию судьями социальных сетей. Так, в США, где социальные сети были впервые (в 1995 году) созданы в известном нам виде, уполномоченные органы 17 штатов уже приняли консультативные заключения по вопросам участия судей в социальных сетях [Дубровин, 2019]. Организацией Объединенных Наций создана Глобальная сеть обеспечения честности и неподкупности судебных органов как интернет-платформа, содержащая кодексы судейской этики стран, материалы практики, другие документы и предоставляющая возможность обмена информацией между судьями по правовым вопросам.

Нормативное определение ориентиров поведения судей в интернетпространстве необходимо. После назначения на должность судьи человек не утрачивает право на общение с друзьями и знакомыми и не должен находиться в социальной изоляции, и именно социальные сети являются одним из способов поддержания общественной активности судей. Надлежащее исполнение судьей своих обязанностей не означает замкнутую и обособленную жизнь. Невозможно понять трансформацию социальных ценностей без знакомства с изменениями, которые происходят в обществе, в том числе в информационной среде. Социальные медиа сегодня составляют фундаментальную часть повседневной жизни, и судьи, чтобы избежать этических «интернет-ловушек», нуждаются в определении критериев их использования. 
Исследователем Бурдиной Е.В. потребность решения этических проблем справедливо отнесена к основным проблемам судей, признана определяющей их наиболее важные интересы, направленные на укрепление гарантий независимости и самостоятельности судебной власти [Бурдина, 2013]. Кодекс судейской этики устанавливает право судьи на обращение в Комиссию Совета судей Российской федерации по этике за получением разъяснения в случае, если судья затрудняется определить, будет ли его поведение в конкретной ситуации отправления правосудия либо во внесудебной деятельности соответствовать требованиям профессиональной этики и статусу судьи. Но не всегда судья вынесет свои этические сомнения и переживания на публичное обсуждение. Поэтому выработка четких рекомендаций относительно пользования судьями социальными сетями необходима. Как отметил председатель Дисциплинарной коллегии судей Рудаков С.В., правила поведения судей, предусмотренные национальными кодексами судейской этики, являются центром внимания и отдельного государства, и всего мирового сообщества [Бурдина, 2013]. На первой встрече Глобальной сети судейской честности в апреле 2018 года представители различных международных и национальных правовых систем указали на необходимость оказания помощи судебным органам в проблемах, с которыми они сталкиваются, в том числе путем проведения программ обучения для судей по использованию социальных сетей; на интернет-платформе Глобальной сети обсуждаются вопросы проведения тренингов по этике судей, создания инструментов обучения судебной этике и включения вопросов использования социальных сетей судьями в учебные курсы для судей.

\section{Заключение}

В истории одни моральные принципы постоянно сменяются на другие, и в условиях глобальной информатизации общества только собственных этических представлений относительно поведения в социальных сетях судьям не хватает.

Одним из способов поддержки социальных связей являются социальные сети. Общих рекомендательных этических правил для формулирования поведения судей в социальных сетях уже недостаточно, поэтому в этой области требуется создание обязательных этических стандартов. Отсутствие критериев участия судей в социальных сетях мешает полноценному формированию профессиональной идентичности судей, и судьи все больше нуждаются в руководстве о том, как им следует вести себя в социальных сетях, им следует знать о последствиях, к которым могут привести безобидные, на первый взгляд, действия в интернете.

Сами по себе, без должного регулирования вопросы участия судей в социальных сетях не разрешатся. Формирование этических норм поведения судьи в условиях современности и глобализации информационного пространства не может не быть частью стратегического направления развития судебной системы в России, а принятие Кодекса судейской этики само по себе не завершает формирования правил этического поведения судей. Необходимыми представляются развитие и конкретизация Кодекса судейской этики в части определения критериев участия судьи в социальных сетях с учетом изменяющихся условий жизни и отечественного и зарубежного опыта.

\section{Список литературы}

1. Бурдина Е.В. 2013. Интересы судей как элемент нормативно-правовой конструкции судейского сообщества в Российской Федерации. Администратор суда, 1: 27-29.

2. Васильева Т.А., Карташкин В.А., Колесова Н.С., Колотова Н.В., Ледях И.А., Лукашева Е.А., Мизулина Е.Б., Нерсесянц В.С., Пчелинцев С.В., Савицкий М.В., Салищева Н.Г. 2009. Права человека. М., Норма, 321 с. 
3. Волков В.В., Дмитриева А.В., Поздняков М.Л., Титаев К.Д. 2015. Российские судьи: социологическое исследование профессии. М., Норма, $272 \mathrm{c.}$

4. Дмитриева А., Савельев Д. 2019. Аналитическая записка «Источники пополнений судейского корпуса РФ и роль аппарата судов». Институт проблем правоприменения. URL: http://www.enforce.spb.ru/products/policy-memo/7123-analiticheskaya-zapiska-istochniki-popolneniyasudejskogo-korpusa-rf-i-rol-apparata-sudov-dmitrieva-a-savelev-d (дата обращения: 25.06.2019).

5. Дубровин Е.В. 2019. Этика поведения судей в социальных сетях (опыт Соединенных Штатов Америки). Pressreader. URL: https://www.pressreader.com/ (дата обращения 26.06.2019).

6. Лагутин Д.С. 2016. К вопросу об истории судейской этики в России. Инновационная наука, 5: 239-242.

7. Лебедева В.А. 2004. Право. Личность. Интернет. М., Волтерс Клувер, 5-7.

8. Нешатаева Т.Н. 2011. Модернизация статуса судьи: современные международные подходы. М., Инфра-М, 336 с.

9. Орлова К.А. 2017. Теоретико-правовые аспекты статуса судьи. Дис. ... канд. юрид. наук. Калининград, $241 \mathrm{c.}$

10. Рассолов И.М. 2009. Право и интернет. Теоретические проблемы. М., Норма, 383 с.

11. Апарова Т.В., Богдановская И.Ю., Егоров С.А., Крутоголов М.А., Крылова Н.С., Попов Н.Ю., Туманов В.А., Урьяс Ю.П. 1991. Судебные системы западных государств. М., Наука, 6 с.

12. Хазиева Н.О. 2014. Виртуальная реальность как пространство социализации: социально-философский анализ проблемы. Автореф... канд. фил. наук. Казань. 19 с.

13. Cooper B.P. 2014. Judges and Social Media: Friends with Costs and Benefits. SSRN (Social Science Research Network) Available at: https://papers.ssrn.com/sol3/papers.cfm?abstract_id=2451094 (accessed 16 June 2019).

\section{References}

1. Burdina E.V. 2013. Interesy sudej kak jelement normativno-pravovoj konstrukcii sudejskogo soobschestva v Rossijskoj Federacii. [Interests of judges as an element of the legal structure of the judicial community in the Russian Federation]. Administrator suda, 1: 27-29.

2. Vasil'eva T.A., Kartashkin V.A., Kolesova N.S., Kolotova N.V., Ledyah I.A., Lukasheva E.A., Mizulina E.B., Nersesyanc V.S., Pchelincev S.V., Savickij M.V., Salishcheva N.G. 2009. Prava cheloveka [Human rights]. Moscow, Norma, 321 p.

3. Volkov V.V., Dmitrieva A.V., Pozdnyakov M.L., Titaev K.D. 2015. Rossijskie sud'i: sociologicheskoe issledovanie professii [Russian judges: a sociological study of the profession]. Moscow, Norma, $272 \mathrm{p}$.

4. Dmitrieva A., Savel'ev D. 2019. Analiti4eskaja zapiska «Istochniki popolnenij sudejskogo korpusa RF i rol' apparata sudov». Institut problem pravoprimenenija [Analytical note "Sources of replenishment of the Russian judiciary and the role of the court apparatus". Institute of law enforcement]. Available at: http://www.enforce.spb.ru/products/policy-memo/7123-analiticheskaya-zapiska-istochnikipopolneniya-sudejskogo-korpusa-rf-i-rol-apparata-sudov-dmitrieva-a-savelev-d (accessed 25 June 2019).

5. Dubrovin E.V. 2019. Jetika povedenija sudej v social'nyh setjah (opyt Soedinennyh 66tatov Ameriki). Pressreader [Ethics of judges ' behavior in social networks (experience of the United States of America)]. Available at: URL: https://www.pressreader.com/ (accessed 26 June 2019).

6. Lagutin D. S. 2016. K voprosu ob istorii sudejskoj jetiki v Rossii. [On the history of judicial ethics in Russia]. Innovacionnaya nauka, 5: 239-242.

7. Lebedeva V.A. 2004. Pravo. Lichnost'. Internet. [Right. Personality. Internet]. Moscow, Volters Kluver, 5-7.

8. Neshataeva T.N. 2011. Modernizacija statusa sud'i: sovremennye mezhdunarodnye podhody. [Modernization of the status of a judge: modern international approaches]. Moscow, Infra-M, $336 \mathrm{p}$.

9. Orlova K.A. 2017. Teoretiko-pravovye aspekty statusa sud'I [Theoretical and legal aspects of the status of a judge]. Dis. ... PhD in law. Kaliningrad, 241 p.

10. Rassolov I. M. 2009. Pravo i internet. Teoreticheskie problem [Law and the Internet. Theoretical problems]. Moscow, Norma, 383 p. 
11. Aparova T.V., Bogdanovskaya I.YU., Egorov S.A., Krutogolov M.A., Krylova N.S., Popov N.YU., Tumanov V.A., Ur'yas YU.P. 1991. Sudebnye sistemy zapadnyh gosudarstv [Judicial systems of Western States]. Moscow, Nauka, 6 p.

12. Hazieva N.O. 2014. Virtual'naya real'nost' kak prostranstvo socializacii: social'no-filosofskij analiz problem [Virtual reality as a space of socialization: socio-philosophical analysis of the problem]. Avtoref... kand. fil. nauk. Kazan'. 19 p. (in Russian)

13.Cooper B.P. 2014. Judges and Social Media: Friends with Costs and Benefits. SSRN (Social Science Research Network) Available at: https://papers.ssrn.com/sol3/papers.cfm?abstract_id=2451094 (accessed 16 June 2019).

\section{Ссылка для цитирования статьи For citation}

Факеева Л.Е. 2020. К вопросу об участии судей в социальных сетях в рамках статуса судьи. NOMOTHETIKA: Философия. Социология. Право. 45 (1): 123-132.

DOI10.18413/2712-746X-2020-45-1-123-132

Fakeeva I.E. 2020. The issue of participation of judges in social networks in the framework of the judge status. NOMOTHETIKA: Philosophy. Sociology. Law. 45 (1): 123132. (in Russian). DOI 10.18413/2712-746X-2020-45-1-123-132 